\title{
Tools for integrating soil and sub-soil in sustainable urban planning
}

\author{
A. Loschetter ${ }^{1}$, A. Baills ${ }^{1}$, F. Taillandier ${ }^{2}$, J. M. Douguet ${ }^{5}$, \\ F. Lebert ${ }^{1}$, J. F. Lataste ${ }^{2}$, D. Breysse ${ }^{2}$, J. M. Valet ${ }^{3}$, M. Dabas ${ }^{3}$ \\ \& M. Garnier ${ }^{4}$ \\ ${ }^{1}$ BRGM, France \\ ${ }^{2}$ I2M, Université de Bordeaux, France \\ ${ }^{3}$ Géocarta, France \\ ${ }^{4}$ Fondaterra, France \\ ${ }^{5}$ REEDS, Université de Saint-Quentin-en-Yvelines, France
}

\begin{abstract}
This work aims at developing the bases necessary for taking into account in an integrated manner the soil and sub-soil issues in urban development. The diversity of actors and of their concerns lead us to develop different tools, with dedicated uses: 1) a multi-actor debate-aid tool based on multi-criteria analysis, that makes more readable the diversity of challenges and viewpoints of actors; 2) a technical aid-tool with a database devoted to stakeholders, that makes an inventory of main issues that may be encountered during typical urban development projects and that enables to agglomerate the information from basic data in order to make it usable in the multi-actor public consultation; 3) a quantitative decision-making aid tool for enlightening the economic value of indispensable investigations. A conceptual framework is proposed, based on the expertise of the project partners in data gathering, in operational urban development or in project management. It is validated and tested on real test cases, corresponding to specific urban projects.
\end{abstract}

Keywords: urban planning, soil, subsoil, multi-criteria multi-actor decision making tool, investigation value. 


\section{Introduction}

Urban systems are built and developed in a natural environment including landscape, soils and sub-soils. This environment constitutes a resource but also a constraint or a source of risk. The interactions between urban and natural environment thus take on a very important social, environmental and economic dimension [1]. Despite that, these problems are generally underestimated, or even, sometimes, forgotten as urban planners often consider them as an engineering concern [2]. Most approaches remain thematic when a sustainable approach would require accounting consistently for these various dimensions. By associating urban actors with scientists, this work aims at developing the bases necessary for integrating the soil and sub-soil issues in urban development. Different tools have been developed for this purpose (as summarized in Table 1) and are presented in following parts.

Table 1: $\quad$ Summary of the different tools developed.

\begin{tabular}{|l|l|l|c|}
\hline \multicolumn{1}{|c|}{ Tool developed } & \multicolumn{1}{|c|}{ Dedicated to: } & Type of analysis & Cf. section: \\
\hline INTEGRAAL & $\begin{array}{l}\text { Tool for multi-actor } \\
\text { debate }\end{array}$ & Multi-criteria & 2 \\
\hline $\begin{array}{l}\text { Checklist and } \\
\text { knowledge forms }\end{array}$ & Project stakeholders & Multi-criteria & 3 \\
\hline $\begin{array}{l}\text { Value of } \\
\text { investigations }\end{array}$ & Project stakeholders & $\begin{array}{l}\text { Monetary/utility } \\
\text { analysis }\end{array}$ & 4 \\
\hline
\end{tabular}

\section{Multi-actor debate-aid tool based on multi-criteria analysis}

March [3] showed that the problem of the public decision-making (and thus in urban planning) is due to the contradictory objectives of the different stakeholders; there is no optimal solution that can be agreed by all the stakeholders. To answer this issue, we propose to use a multi-criteria debate method: INTEGRAAL (developed by REEDS-UVSQ) [4, 5] is implemented to promote the integration of soil and subsoil in urban projects. It identifies six consecutive steps (Identify, Structure, Inform, Evaluate, Communicate, and Reflect on outcomes) of a recursive process of multi-criteria and multi-actor evaluation. This evaluation aims at making more readable the diversity of challenges and viewpoints associated with a project and at engaging actors in a consultation process [5].

Although presented here as a sequence of steps, INTEGRAAL should not be conceived as a rigidly linear process. The principle is to constitute a "deliberation forum" that offers opportunities to participants to explore progressively, or in parallel, different aspects of the problem. Deliberation exercises can be iterative, allowing participants to go deeper and to gain or exploit more detailed information. The consecutive steps are detailed below. 


\subsection{Step ONE: identify}

The first step of the process is the identification by the stakeholders of actors, of challenges and possible scenarios. This task delivers the context, the scale, and the dynamics of the exercise.

\subsection{Step TWO: structure}

This means developing in a pragmatic way, typologies or classifications for:

a. the actors who are involved;

b. the policies, strategy options, or scenarios to be appraised;

c. the challenges against which the performance of the policies, options or scenarios will be appraised (e.g.: preservation of the environment).

\subsection{Step THREE: inform}

The identification and mobilization of information and tools for system representation (e.g., maps, models of processes and systems) can help to anchor the deliberations in a robust knowledge base. This step is fueled between others by the information provided by the technical aid-tool (cf. section 3). This step leads to the definition of indicators, which are units of information obeying to certain structural qualities.

\subsection{Step FOUR: evaluate}

This step relies on the framework and information developed in steps 1-3 above. It produces outcomes in the formal sense of a multi-actor multi-criteria evaluation. It also provides insights and learning to participants via the discussions that take place and observation of the respective positions adopted and of how these evolve through the collective learning that occurs. An overview of the "evaluation" step in the software is provided in Figure 1.

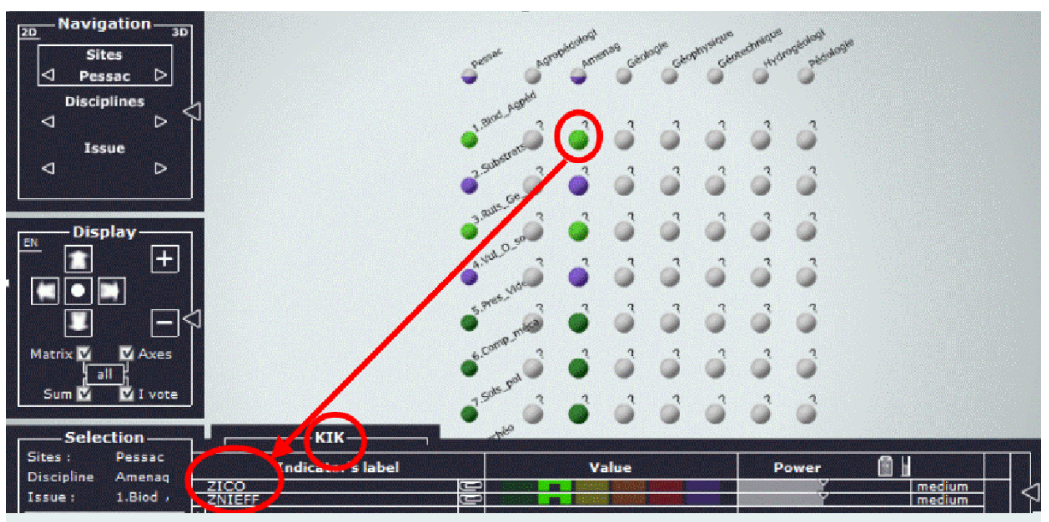

Figure 1: Overview of the tool interface for the evaluation step. 


\subsection{Step FIVE: communicate}

This step includes all tasks of information sharing (including the final reporting stages of the evaluation exercise) and of information management.

\section{Technical aid-tool based on risk analysis}

Technical aid-tool is a risk based tool for urban planning projects allowing identifying and assessing risk relating to soil and sub-soil. Project risk can be defined as effect of uncertainties on project objectives (cost, time and project performance) [6]. This technical tool enables accessing:

- a checklist of questions to enable a non-specialist to ask himself all the relevant questions;

- a database that highlights the soil/subsoil topics potentially impacting urban development projects;

- a database gathering the soil and subsoil means of investigation.

\subsection{Checklist}

In order to highlight the relations between the project and its soil and sub-soil, and in order to guarantee that all issues are adequately taken into account, we developed a checklist. It consists in a series of questions dedicated to the selfevaluation of the project by the stakeholders. It gives a first approach to identify risks related to soil and sub-soil for an urban planning project.

The questions are gathered, depending on their relation to the project itself, to the soil and subsoil or to externalities. In addition, the checklist enables to identify which questions concern the regulatory obligations, the technicaleconomic aspects, the social acceptability and the opportunities. This double entry table (Figure 2) is thus oriented to the project stakeholders' expectations.

\subsection{Database for the questions of the checklist}

Many soil/subsoil topics can impact urban development projects, either because they appear as constraints or opportunities, or because they impact the technical feasibility or the costs. As the questions are exposed very briefly in the checklist, the non-expert user may legitimately expect more information. Therefore, we elaborated a database that proposes a form for each question of the checklist. It contains the following information: definition, consequence, examples, methods for investigating the question, regulatory obligations, useful links, etc.

\subsection{Database for the methods of investigations}

The questions forms mention the methods for investigating the soil and subsoil issues, and the non-expert user may need more information on the possible investigation methods. Hence, we elaborated a database that proposes a form for each method of investigation, which contains the following information: definition, advantages, drawbacks and limits, costs, questions that the method 
enables to answer, useful links, etc. Note that a method can bring information on several questions, and is thus useful complementary to several questions forms.

In order to know if an investigation method is worth being carried out, we propose a quantitative decision-making aid tool for determining the value of information brought by investigations.

Checklist to verify proper consideration of issues related to soil / subsoil in projects Warning: read the "To Read" information tab before using

\begin{tabular}{|c|c|c|c|c|c|}
\hline & $\begin{array}{c}\text { Blockage, } \\
\text { regulatory } \\
\text { requerem } \\
\text { ent }\end{array}$ & $\begin{array}{l}\text { Technico- } \\
\text { economic } \\
\text { (cost, } \\
\text { delay) }\end{array}$ & $\begin{array}{c}\text { Social } \\
\text { accepta- } \\
\text { bility }\end{array}$ & $\begin{array}{l}\text { Opportu- } \\
\text { nity }\end{array}$ & Other \\
\hline \multicolumn{6}{|c|}{ Matters for which the aspect "EXTERNALITIES" is predominant } \\
\hline $\begin{array}{l}\text { Is the project consistent with PLU/SCOT( SCOT: « schéma de } \\
\text { cohérence territoriale » / Urban master plans and PLU: "plan } \\
\text { local d'urbanisme"/simplified zonation of hazard, « which can } \\
\text { include ban to construct »)? }\end{array}$ & +++ & & & & \\
\hline $\begin{array}{l}\text { Is the plot concerned by a PPRN or PPRI (PPRN: "Plans de } \\
\text { Prévention des Risques Naturels prévisibles"/Plan of } \\
\text { prevention of foreseeable natural hazards and PPRI: "Plan de } \\
\text { Prévention des Risques d'Inondation/Plan of prevention of } \\
\text { flood risks)? }\end{array}$ & ++ & & & & \\
\hline $\begin{array}{l}\text { Is there biodiversity to protect (fauna/flora)? Is the site } \\
\text { situated in wetlands, protected natural area, etc? }\end{array}$ & +++ & ++ & + & + & \\
\hline $\begin{array}{l}\text { Is the plot situated in a cultural heritage area (archaeology, } \\
\text { historical monuments...) or in a military/war area (bombs...)? }\end{array}$ & +++ & +++ & + & + & \\
\hline Has an impact survey been conducted? & +++ & & & & \\
\hline Are there networks close to the project or nearby? & ++ & ++ & + & ++ & \\
\hline \multicolumn{6}{|c|}{ Matters for which the aspect "PROJECT" is predominant } \\
\hline $\begin{array}{l}\text { Do the mecanical properties of soil and subsoil mach with the } \\
\text { nature of the project? (geotechnical potential, stability, etc) }\end{array}$ & + & +++ & & & \\
\hline Will the project impact hydrology and hydrogeology? & + & ++ & + & & \\
\hline $\begin{array}{l}\text { Had the life cycle of materials used / produced by the project } \\
\text { been taken into account? (especially regarding soil and } \\
\text { subsoil: futur of excavated materials) }\end{array}$ & & + & + & ++ & \\
\hline $\begin{array}{l}\text { Are there land use conflic with other project (old } \\
\text { underground works disused or still used)? }\end{array}$ & + & + & + & + & \\
\hline \multicolumn{6}{|c|}{ Matters for which the aspect "SOIL" is predominant } \\
\hline Are the soils polluted? Is it necessary to rid of pollution? & + & +++ & +++ & & \\
\hline $\begin{array}{l}\text { Has the geothermal potential of the area been taken into } \\
\text { account in the project development? }\end{array}$ & & + & + & ++ & \\
\hline Are there risks linked with natural or anthropic gas emission? & & + & +++ & & \\
\hline Are there risks linked to natural or anthropic cavity? & & ++ & ++ & & \\
\hline Are there landslide risks? & & ++ & ++ & & \\
\hline Are there risks of withdrawal-swelling of clay soils? & & ++ & ++ & & \\
\hline Are there flood risks on the site? & & ++ & ++ & & \\
\hline Are there risks linked to seismicity on the site? & & ++ & +++ & & \\
\hline \multicolumn{6}{|c|}{ Other matters to consider } \\
\hline & & & & & \\
\hline
\end{tabular}

Figure 2: $\quad$ Checklist presentation. 


\subsection{Tool presentation}

The tool (French version) will be available online, with links between the different parts of the tool: the user may click on a question in the checklist in order to open the corresponding form. In the question form, links towards the relevant investigation methods forms will be available, and vice-versa.

\section{Quantitative decision-making aid tool for determining the value of investigations}

\subsection{Objective}

In order to minimize an urban project risks, everybody agrees on the importance of soil and subsoil investigations. Nevertheless, stakeholders are always facing some economic constraints, and avoiding any preliminary investigations may appear as an easy option. Therefore, we considered the development of a tool for enlightening the economic value of indispensable information. The objective of such a tool is to help stakeholders deciding which investigations are worth being carried out (those which provide information that reduces "unexpected" costs, that can be much higher than the investigation costs), and which ones are not.

Such a tool should take into account:

- The investigation costs of the different methods;

- The probabilistic impact (cost, delay and performance impact) of risks;

- The reliability of each method for providing information on each risk;

- The fact that some methods may provide information on several risks;

- The fact that stakeholders may be risk-adverse, that is to say that they may prefer minimizing risks.

\subsection{Method}

To achieve this, we developed a quantitative decision-making aid tool for determining the value of information, and then deducing if the information is worth being acquired.

The model consists in assessing 3 possibilities:

i. A base case situation, which consists in choosing the most economical technical solution (lower direct costs, implying that is the less cautious option), without taking into account the fact that this option may be more risky and generate unexpected costs, thus making the base case reference not the most economical in fine.

ii. An intermediate situation, that consists in taking into account existing data in order to analyze risk and choose consequently the best compromise between economical and cautious solution.

iii. An informed situation that considers the possibility to carry out field investigations to obtain supplementary specific data, thus enabling to choose the adapted technical situation depending on field investigations results. Note that the assessment of this situation is performed prior to 
any real field investigations; it is based on probabilistic analysis. In addition to the economic value of this situation, the model provides the list of field investigations which are worth being carried out.

The process is composed of several steps:

a. Risk assessment (probability and consequences);

b. Expression of consequences in terms of utility;

c. Risk, consequences and value calculation for the base case situation (i);

d. Determination of technical optimal solutions and calculation of consequences and value for the intermediate situation (ii);

e. Calculation of investigation methods performance, of conditional probabilities considering that the method is carried out, simulations with Monte Carlo analysis, calculation of consequences and value for the informed case (iii), determination of the value of information provided by each investigation method.

The optimization for obtaining the optimal solution of each situation allows for:

- The direct over-cost of the project (difference between the chosen solution and the most economical solution);

- The probabilistic cost of the risks (consequences of uncertainties);

- The cost of investigation carried out (for situation (iii));

- The delays that are provoked by the occurrence of an impact.

\subsubsection{Inputs}

The input parameters that need to be completed by the user are the followings:

- Data related to the different hazards, based on generic information (probability of occurrence, discrete probability distribution of impacts characterized by their potential costs and delays). These costs and delays are indicated for the most economical technical solution (high costs and delays) and for the most cautious solution (lower costs and delays);

- Data related to investigation methods (relevancy and precision of each method for detecting each kind of hazard);

- Data related to the utility function that characterizes the risk aversion of the decision-maker.

\subsubsection{Expression of consequences in terms of utility}

Resorting to different scales (as in multi-criteria analysis) does not enable formal optimization. Therefore, a UTA approach [7] is used. Costs and delays are expressed on a single scale of utility (Figure 3 \& Figure 4), which will make optimization possible. It is also therefore possible to account for the potential risk aversion of the decision maker.

\subsubsection{Calculation of risk and value for the base case situation (i)}

The only elements involved for computing the value of the most economical solution (i) are the cost and delays of potential impacts. Thus, the calculation consists in transforming costs and delays on the above-mentioned utility scales, and then in computing the average impact (multiplication of consequences and probability). 


\subsubsection{Calculation of risk for the intermediate situation (ii)}

For assessing this situation (that consists in taking into account existing data in order to analyze risk and choosing consequently the best compromise between economical and cautious solution), the process is the following:

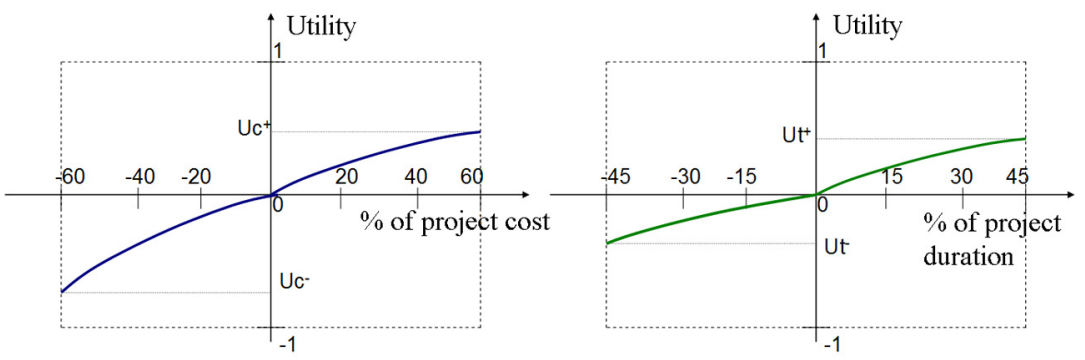

Figure 3: $\quad$ Examples of utility curves for project cost and delay.

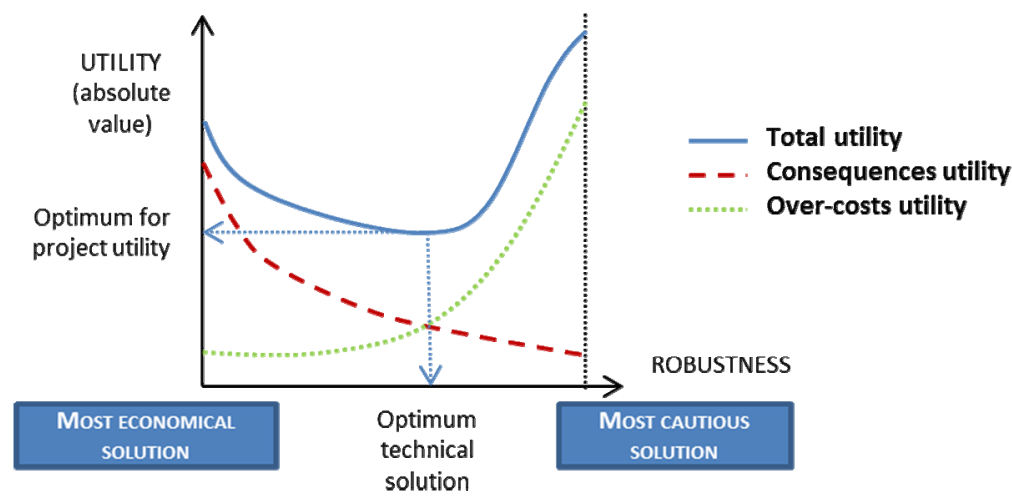

Figure 4: Research of the technical optimum between the most economical and the most cautious solutions.

- For each hazard, we consider 11 levels of refinement for the technical solution (level 0: most economical solution; level 10: most cautious solution). For each level of technical solution, the following elements (converted in utility values) are added: costs and delays of potential impacts, over-costs due to the choice of a solution that is more cautious than the economical solution.

- The level that reaches an optimum is retained for each hazard.

- The utility value of the project is obtained by summing the values obtained for the different hazards.

\subsubsection{Calculation of risk and value for the informed situation (iii)}

Based on occurring probabilities of hazards and on relevancy and precision of methods, the probability to better identify a specified hazard with a specified 
method is computed using conditional probabilities (Bayesian law). Depending on the results provided by investigations, the optimal technical solution is determined. Thus, by performing a large number of Monte Carlo simulations, it becomes possible to identify the optimal solution for each case (taking into account costs and delays of potential impacts, over-costs due to the choice of a solution that is more cautious than the economical solution, costs of investigations). This step enables to identify the most valuable methods, and to determine which ones are worth being carried out (the ones whose utility is positive). A fictitious example is presented in part (iii) of Figure 5.

\subsection{Results synthesis}

The tool highlights the economic interest of the approach, by giving evidence that data gathering and prior soil investigations may have an economic positive impact on a project. The results of the tool are presented in a synthesized sheet, as presented in Figure 5 (data are fictive).

\section{Application of the methodology}

\subsection{Presentation of the site and planning context}

Pessac municipality is located south of Bordeaux (Figure 6(a)). The experimental site is composed of 4 plots of $1000 \mathrm{~m}^{2}$ each in the Artigon area. The planning project is composed of 4 different projects of eco-neighborhood.

In order to highlight the possible soil and subsoil issues, the checklist of the technical aid-tool (see section 3) has been used: bibliography underlines some hazards that could impact the project at the different states of development (definition, construction, exploitation). Those hazards are namely: shrinkage and swelling of clayey soils (more than 200 events in this town since 1989) [8], possible archaeological issues and hazards associated with shallow groundwater (wetlands and nearby Ars stream). The area is divided in 4 plots, which are crossed by the Ars stream. The shallow groundwater of the sandy-clay layer (0 to $8 \mathrm{~m}$ deep) presents a piezometric level often close to the surface during high water period and fluctuates depending on weather conditions. Surveys conducted by Environment RCT in April 2011 showed a piezometric level at the depth of 2 meters.

\subsection{Building the profile of the area thanks to the INTEGRAAL method}

In order to build the risk profile of the Artigon area in Pessac, we followed the different steps of the INTEGRAAL method (see section 2).

We implemented a progressive approach adapting and combining techniques based on the data acquired in the previous step. This methodology allows refining step by step the knowledge on subsoil; focusing efforts on key issues which are in this case properties variability in the first 3 meters. Mapping helps to focus the study on a highly heterogeneous area [9]. 


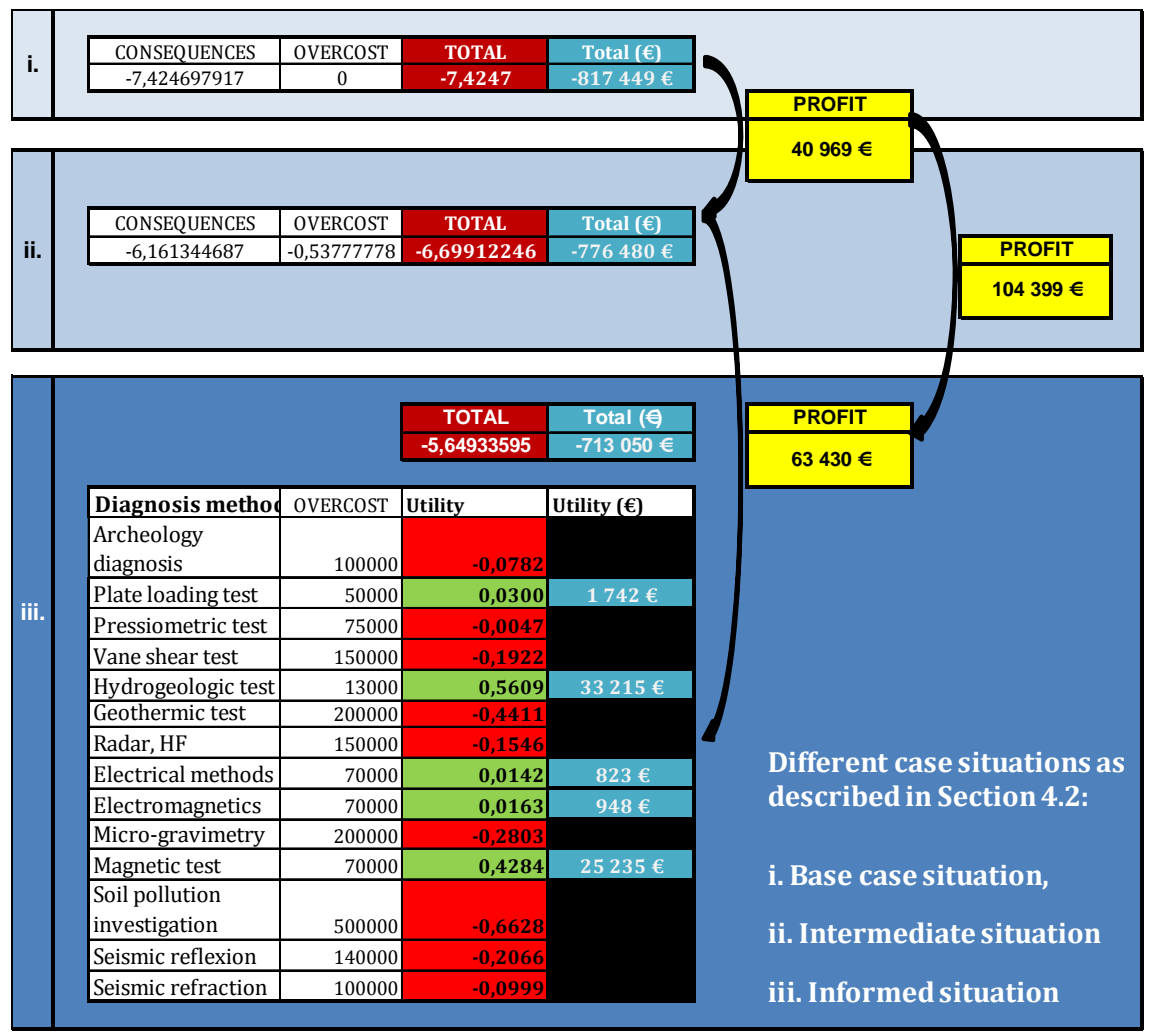

Figure 5: $\quad$ Presentation of the tool results synthesis.

(a)

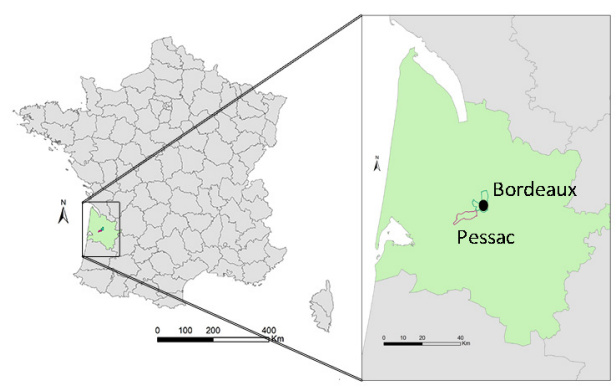

(b)

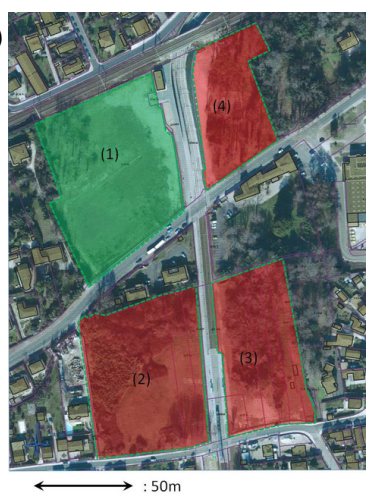

Figure 6: $\quad$ Location of the site (a) and detail of the 4 plots of the site (b).

A possibility of hazard occurrence is attributed to each elementary volume. Thanks to this preliminary survey, which combined several exploration techniques, the decision maker gets more precise quantified data (in particular 
the nature, extent and location of the hazard area) that can be useful in the decision process throughout the project. The first three steps are achieved and the fourth one is currently undergoing.

\subsection{Comparison of the projects}

A second opportunity to mobilize knowledge about soil and sub-soil is the comparison of development projects using INTEGRAAL. The "structuration" step enabled to classify the planning projects to assess, the challenges to deal with and the involved stakeholders. We aggregated the results within the KerBabelTM Deliberation Matrix [10] (see Figure 7).

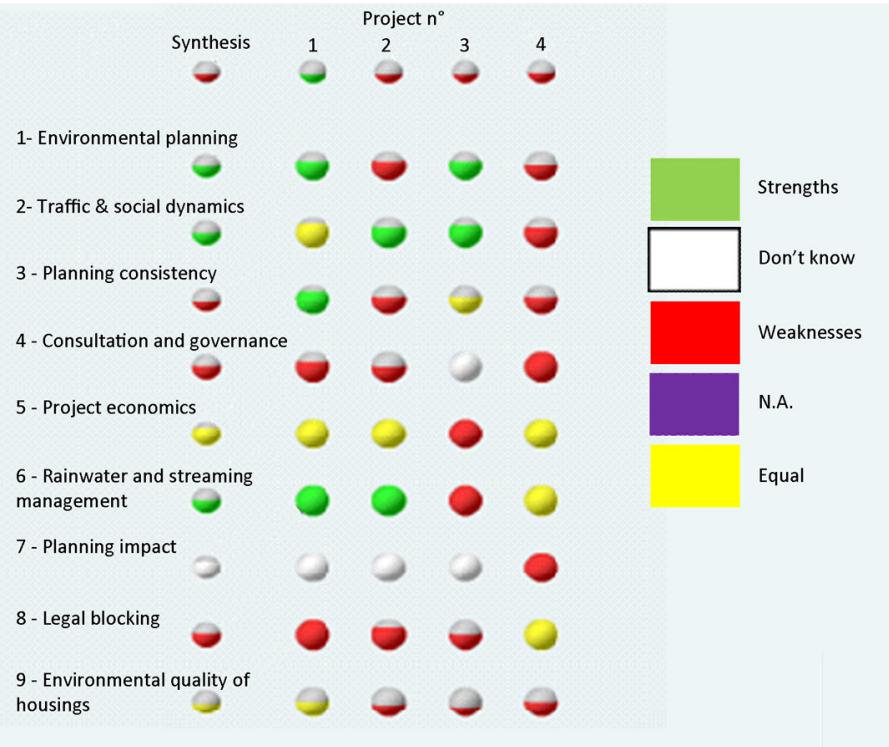

Figure 7: $\quad$ Synthetic presentation of projects comparison evaluating 4 projects over 9 challenges.

\section{Conclusion}

This work proposes a conceptual framework, based on the expertise of the different actors involved in data gathering, in operational urban development and in project management. It has been validated and tested on real test cases corresponding to specific urban projects such as the Artigon eco-neighbourhood project in Pessac municipality.

This work provides decision makers and urban planners with necessary information to sustainably adapt the project development to the area considered and avoid delays and extra-costs often related to poor prior knowledge of soil and sub-soil characteristics.

The methodology also included experimental phases focusing on ground investigation in order to test the adequacy of investigations in the context of 
urban development (not presented in this paper). The ability of geophysical and geotechnical methods, used alone or in combination, has in particular been quantified during these investigations.

\section{Acknowledgements}

This work is co-funded by the French National Agency of Research under the project D2SOU (for consideration of the soil and sub-soil as a criterion for sustainability planning operations, website in French: www.d2sou.com), contract $\mathrm{n}^{\circ}$ ANR-09-VILL-0005 and approved by the 2009 "Villes Durables" program (sustainable cities). We thank C. Piette from Pessac municipality and J. P. Lammens form SEP86 for providing us with study sites and corresponding data.

\section{References}

[1] Parriaux, A., Blunier, P., Maire, P., Dekkil, G. \& Tacher, L., (eds). Projet Deep City: Ressources du sous-sol et développement durable des espaces urbains, Rapport de recherche PNR 54, 2010.

[2] Barles, S., City planning and underground space in $20^{\text {th }}$ and $21^{\text {st }}$ century France. Proc. of Going Underground: Excavating the Subterranean City, Manchester, 21st-22nd September 2006.

[3] March, J. G., Bounded rationality, ambiguity, and the engineering of choice. Decision making: descriptive, normative, and prescriptive interactions, ed. D.E. Bell, H. Raiffa \& A. Tversky, Cambridge University Press.: Cambridge, UK, 1988.

[4] Stirling, A., Multi-criteria mapping, mitigating the problems of environmental valuation. Valuing Nature, Ethics, Economics and the Environment, ed. J. Foster, Routledge: London, 1997.

[5] O'Connor, M. The “four spheres” framework for sustainability. Ecological Economics, 3(4), pp. 285-292, 2007.

[6] Mehdizadeh, R., Taillandier, F., Breysse, D. \& Niandou, H., Methodology and tools for risk evaluation in construction projects using Risk Breakdown Structure. European Journal of Environmental and Civil Engineering, 16, pp. 78-98, 2012.

[7] Jacquet-Lagreze, E., \& Siskos, Y., Assessing a set of additive utility functions for multicriteria decision making: the UTA method. European Journal of Operational Research, 10, pp. 151-164, 1982.

[8] Chrétien, M., Fabre, R., Denis, A. \& Marache, A., Analyse des sinistres liés au retrait-gonflement des sols argileux en Gironde. Proc. 25e rencontres de l'AUGC, Bordeaux, 23-25 May 2007.

[9] Guerrero, O., Marache, A., Lataste, J.F. \& Breysse, D., Caractérisation de la variabilité spatiale des sols par fusion de données géophysiques. Proc. of Congrès Français de Mécanique, Bordeaux, August 2013.

[10] O’Connor, M., (eds). The KerBabel Indicator Dialogue Box: Generic Design Specifications for the "Indicator Dialogue Box"-Version 3, Rapport de Recherche du C3ED, Guyancourt, Université de Versailles, StQuentin-en-Yvelines, 2004. 